\title{
Soshiho-tang water extract inhibits ovalbumin-induced airway inflammation via the regulation of heme oxygenase-1
}

\author{
Woo-Young Jeon ${ }^{1,3}$, Hyeun-Kyoo Shin ${ }^{1}$, In-Sik Shin², Sang Kyum Kim³ and Mee-Young Lee ${ }^{1 *}$
}

\begin{abstract}
Background: Soshiho-tang, known as Xio-hai-Hu-Tang in Chinese and Sho-Saiko-to in Japanese, has been widely used as a therapeutic agent. Its pharmacological effects include anti-inflammatory, antioxidant, antihepatic fibrosis, antitumor and immunomodulating activities. However, little is known regarding its effects on allergic asthma. Therefore, the aim of the present study was to investigate whether the Soshiho-tang water extract (SSTW) has antiasthmatic effects on airway inflammation in an ovalbumin (OVA)-induced mouse model.

Methods: BALB/c mice were used as a model of asthma after induction by sensitization and challenge with OVA. We measured change in eosinophils, other inflammatory cells, and T helper 2 (Th2)-type cytokines, such as interleukin (IL)-4, IL-5, IL-13, IL-17, IL-33, and chemokine (eotaxin) in bronchoalveolar lavage fluid (BALF), presence of total and OVA-specific immunoglobulin (Ig)E in plasma, and expression of mucus production and heme oxygenase $(\mathrm{HO})-1$ protein in lung tissue.
\end{abstract}

Results: Our results show that SSTW had a suppressive effect on eosinophil influx into BALF and decreased the levels of Th2-type cytokines. Moreover, SSTW exhibited a marked decrease in mucus hypersecretion, total and OVA-specific lgE levels, and significantly induced HO-1 protein expression.

Conclusions: These results suggest that SSTW may be used as a valuable therapeutic agent for treating various inflammatory diseases including allergic asthma.

Keywords: Soshiho-tang, Asthma, Eosinophils, Th2-type cytokines, IgE, Heme oxygenase-1

\section{Background}

Asthma is a complex disorder associated with T helper 2 (Th2) immune responses to allergens characterized by airway obstruction and pulmonary inflammation that affects approximately 300 million people worldwide [1]. It is now well recognized that asthma is caused by Th2-driven inflammatory responses, which enhance airway eosinophilia and lung mucus production [2]. Allergic immune response is initiated by activation of allergen-specific Th2 cells, release of the Th2-type cytokines interleukin (IL)-4, IL-13 coupled with an increase in immunoglobulin (Ig)E, and localized eosinophilia [3].

\footnotetext{
* Correspondence: cozy11@kiom.re.kr

${ }^{1}$ K-herb Research Center, Korea Institute of Oriental Medicine, 1672 Yuseong-daero, Yuseong-gu, Daejeon 305-811, Republic of Korea Full list of author information is available at the end of the article
}

$\mathrm{CD}_{4}^{+} \mathrm{T}$-cells play a crucial role in immune protection via their capacity to help B cells make antibodies, recruit eosinophils to sites of inflammation, and through their production of cytokines and chemokines [4]. Th2-type cytokines, including IL-4, IL-5, IL-13, IL-17, and IL-33 produced by activated $\mathrm{CD}_{4}^{+} \mathrm{T}$-cells, enhance IgE production, eosinophil accumulation [5], and play a central role in the pathogenesis of asthma [6]. Therefore, suppression of Th2-type cytokine production by activated $\mathrm{CD} 44^{+} \mathrm{T}$-cells may prove to be a useful therapeutic approach to the treatment of inflammatory immune diseases such as allergic asthma.

A stress-response protein, heme oxygenase ( $\mathrm{HO})-1$, is a cytoprotective mechanism against oxidative cellular injury [7]. It is induced by various stress stimuli, including hemin, oxidative stress, endotoxins, and hypoxia in various cell types [8]. Resent, basic study show that HO-1, a 
protective gene, and its overexpression have significant cytoprotection properties such as antioxidative and antiinflammatory effects as well as mediation of cell-cycle activities [9]. Therefore, the present study focused on whether Soshiho-tang has an antiasthmatic effect via upregulation of $\mathrm{HO}-1$ in an ovalbumin (OVA)-induced asthmatic model.

Soshiho-tang, known as Xio-Chai-Hu-Tang in Chinese and Sho-Saiko-to in Japanese, is frequently used for treatment of pulmonary disorders such as the common cold and pneumonitis [10]. It is composed of seven herbs: Bupleuri Radix, Scutellariae Radix, Ginseng Radix, Pinelliae Tuber, Glycyrrhizae Radix et Rhizoma, Zingiberis Rhizoma Crudus, and Zizyphi Fructus (Table 1). According to previous experimental reports, Soshiho-tang has a variety of confirmed pharmacological effects such as antiinflammatory [11], antioxidant [12], and immunoregulation [13] activities. Several biological activities of Soshiho-tang have been reported to date; however, there are still no valid studies of its underlying OVA-induced asthmatic effects. Therefore, we investigated the antiallergic effect related to inflammation and oxidative stress of Soshiho-tang water extract (SSTW) on the treatment of bronchial asthma using an OVA-induced mouse model. To our knowledge, this is the first study to provide experimental evidence that Soshiho-tang has antiasthma effects in an OVA-induced murine asthma model.

\section{Methods}

\section{Preparation of the SSTW}

The water extract of Soshiho-tang (2008-KE26) was deposited in the K-herb Research Center, Korea Institute of Oriental Medicine (KIOM). Soshiho-tang was prepared in our laboratory from a mixture of chopped crude herbs purchased from Omniherb (Korea) and HMAX (China). The identity of each crude herb was confirmed by Professor Je-Hyun Lee at the Oriental College of Dongguk University (Gyeongju, Republic of Korea). A herbal decoction of Soshiho-tang was prepared with a mixture of herbal medicines according to composition in

Table 1 Crude components of Soshiho-tang

\begin{tabular}{llll}
\hline Scientific name & Amount $(\mathrm{g})$ & $\begin{array}{l}\text { Company } \\
\text { of purchase }\end{array}$ & Source \\
\hline Bupleuri Radix & $11.25(31.6 \%)$ & Omniherb & Korea \\
Scutellariae Radix & $7.5(21.1 \%)$ & HMAX & China \\
Ginseng Radix & $3.75(10.5 \%)$ & Omniherb & Korea \\
Pinelliae Tuber & $3.75(10.5 \%)$ & Omniherb & Korea \\
Glycyrrhizae Radix & $1.875(5.3 \%)$ & HMAX & China \\
et Rhizoma & & & \\
Zingiberis Rhizoma Crudus & $3.75(10.5 \%)$ & Omniherb & Korea \\
Zizyphi Fructus & $3.75(10.5 \%)$ & Omiherb & Korea \\
Total amount & $35.625(100 \%)$ & & \\
\hline
\end{tabular}

the laboratory (Table 1). The aqueous preparation were extracted in distilled water at $100{ }^{\circ} \mathrm{C}$ for $120 \mathrm{~min}$. The extract solution was evaporated to dryness and then frozen to dry powder (yield, $22.9 \%$ ). The extracted Soshiho-tang powder was stored at $4{ }^{\circ} \mathrm{C}$.

\section{Animals}

Specific pathogen-free female BALB/c mice (seven weeks old) were purchased from the Orient Co. (Seoul, Korea). Mice were maintained in an animal facility under standard laboratory conditions for 1 week of quarantine and acclimatization prior to experiments, and provided water and standard chow ad libitum. The animal experimental procedures were approved by the Korea Institute of Oriental Medicine Institutional Animal Care and Use Committee and performed in compliance with the National Institute of Health Guidelines for the care and use of laboratory animals and the Korean National Animal Welfare Law.

\section{Induction of allergic asthma and experimental design}

To induce asthma, OVA sensitization and airway challenge were performed as described previously [14, 15]. The mice were sensitized on days 0 and 14 by intraperitoneal injection of $20 \mu \mathrm{g}$ OVA emulsified in $2 \mathrm{mg}$ aluminum hydroxide in $200 \mu \mathrm{L}$ phosphate buffered saline (PBS) buffer ( $\mathrm{pH} 7.4$ ). On days 21,22 , and 23 , the mice received an airway challenge with OVA $(1 \%, \mathrm{w} / \mathrm{v}$, in PBS) for $1 \mathrm{~h}$ using an ultrasonic nebulizer (NE-U12; Omron Corp., Tokyo, Japan). SSTW was completely dissolved in PBS and was prepared fresh daily before each treatment. SSTW was administered by oral gavage to mice at doses of 100 and $200 \mathrm{mg} / \mathrm{kg}$ once daily from days 18 to 23. Negative and positive control mice were orally administered PBS and montelukast (Mon, $30 \mathrm{mg} /$ $\mathrm{kg}$ in PBS), respectively. Mon is a potent, selective cysteinyl leukotriene $1\left(\mathrm{CysLT}_{1}\right)$ receptor antagonist [16] and was introduced into the market after successful clinical evaluation in patients with aspirin-sensitive asthma, nocturnal exacerbation of asthma, and allergic asthma [17].

At the end of OVA challenge, bronchoalveolar lavage fluid (BALF) samples were obtained from the trachea of mice and processed. Inflammatory cells were counted as described previously $[14,15]$. In brief, the mice were sacrificed by intraperitoneal injection of pentobarbital (50 mg/kg; Hanlim Pharm. Co., Seoul, Korea) 48 h after the last challenge, and a tracheostomy was performed. To collect the BALF, ice-cold PBS $(0.5 \mathrm{~mL})$ was infused into the lung and withdrawn through tracheal cannulation three times (total volume $1.5 \mathrm{~mL}$ ). The total inflammatory cell numbers were assessed by counting cells in at least five squares of a hemocytometer after exclusion of dead cells by trypan blue staining. To determine differential cell counts, $100 \mu \mathrm{L}$ of BALF was centrifuged 
onto slides using a Cytospin unit (Hanil Science Industrial, Seoul, Korea) $\left(200 \mathrm{~g}, 4{ }^{\circ} \mathrm{C}, 10 \mathrm{~min}\right)$. The slides were dried, and the cells were fixed and stained using DiffQuik $^{\circledR}$ staining reagent (B4132-1A; IMEB Inc., Deerfield, IL), according to the manufacturer's instructions. The supernatant obtained from BALF was stored at $-70{ }^{\circ} \mathrm{C}$ for biochemical analysis. Blood samples were obtained from the mice via the inferior vena cava. Plasma was collected via centrifugation $\left(200 \mathrm{~g}, 4{ }^{\circ} \mathrm{C}, 10 \mathrm{~min}\right)$ and stored at $-70{ }^{\circ} \mathrm{C}$.

\section{Measurement of the levels of Th2-type cytokines and che-} mokine in BALF

The levels of IL-4, IL-5, IL-13, IL17, IL-33 and eotaxin in BALF were measured using enzyme-linked immunosorbent assay (ELISA) kits (BioSource International, Camarillo, CA) according to the manufacturer's protocols. The detection range of $\mathrm{IL}-13$ is $3.9 \mathrm{pg} / \mathrm{mL}$ to $250 \mathrm{pg} / \mathrm{mL}$, and IL-17 is $7.1 \mathrm{pg} / \mathrm{mL}$ to $450 \mathrm{pg} / \mathrm{mL}$, and IL-5 is $7.8 \mathrm{pg} / \mathrm{mL}$ to $500 \mathrm{pg} / \mathrm{mL}$. The detection ranges of IL- 4 are $15.6 \mathrm{pg} / \mathrm{mL}$ to $1000 \mathrm{pg} / \mathrm{mL}$, and eotaxin and IL33 are $31.25 \mathrm{pg} / \mathrm{mL}$ to $2000 \mathrm{pg} / \mathrm{mL}$.

\section{Measurement of total and OVA-specific IgE in plasma}

The levels of total IgE and OVA-specific IgE in plasma were measured as described previously [18]. Microtiter plates were coated with anti-IgE antibodies (anti-mouse IgE; $10 \mathrm{~g} / \mathrm{mL}$; Serotec, Oxford, UK) in PBS-Tween 20, and incubated with plasma sample. The plates were then washed four times, and $200 \mu \mathrm{L}$ of o-phenylenediamine dihydrochloride (Sigma-Aldrich, St. Louis, MO) was added to each well. The plates were incubated for $10 \mathrm{~min}$ in the dark and the absorbance was then measured at $450 \mathrm{~nm}$.

\section{Lung tissue histopathological studies}

For histopathological examination, the lung tissues were stained as described previously [19]. The $4 \%$ paraformaldehyde-fixed tissues were embedded in paraffin, sectioned at $4 \mu \mathrm{m}$ thickness, and stained with hematoxylin and eosin (H\&E) stain solution (hematoxylin; Sigma MHS-16 and eosin; Sigma HT110-1-32) and periodic acid - Schiff (PAS) (IMEB Inc., San Marcos, CA) to measure inflammatory cell accumulation and mucus production, respectively. Quantitative analysis for airway inflammation and mucus secretion was evaluated using a MetaMorph Offline version 7.7.0.0 image analysis software (Molecular Devices Inc., Sunnyvale, CA, USA).

\section{HO-1 enzyme activity in lung tissue}

HO-1 enzyme activity was assessed as described previously [19]. Briefly, lungs were homogenized on ice in one volume of $100 \mathrm{mmol} / \mathrm{L}$ phosphate buffer with $2 \mathrm{mmol} / \mathrm{L} \mathrm{MgCl}_{2}$, and centrifuged for $15 \mathrm{~min}$ at $18,800 \mathrm{~g}$. The supernatant was used to measure HO-1 enzyme activity. ELISA assays were performed according to the manufacturer's instructions. The HO-1 level in lung tissue was estimated using a specific mouse HO-1 ELISA kit (DAKARA, Japan). Activity values were expressed on a per-mg-protein basis.

\section{Immunohistochemistry}

Immunohistochemistry assay were performed as described previously [19]. Paraffin sections were deparaffinized, dehydrated, and washed in PBS with $0.3 \%$ Triton $\mathrm{X}-100$. Slides were preincubated for $10 \mathrm{~min}$ at room temperature with $10 \%$ goat serum to block nonspecific staining, and then incubated with mouse anti-rabbit HO-1 primary antibody (1:200; Abcam, Cambridge, UK) overnight at $4{ }^{\circ} \mathrm{C}$. After removal of primary antibody, slides were washed and incubated with biotinylated secondary antibody at $37{ }^{\circ} \mathrm{C}$ for $1 \mathrm{~h}$ and then with the avidin-biotin-peroxidase complex (Vector Laboratories, Burlingame, CA) for $1 \mathrm{~h}$ at room temperature. Excess secondary antibody was removed, and slides were washed with PBS and incubated with $0.05 \%$ diaminobenzidine (1:200; Millipore, Billerica, MA) for $10 \mathrm{~min}$. Sections were counterstained, rinsed in PBS to terminate the reaction, and coverslipped for microscopic examination.

\section{Image capture and photomicrography}

Photomicrographs were taken using a Photometric Quantix digital camera running a Windows program, and montages were assembled in Adobe Photoshop 7.0. Images were cropped and corrected for brightness and contrast, but were not otherwise manipulated as described previously [18].

\section{Statistical analysis}

Data are expressed as means \pm standard error of the mean (SEM). Statistical significance was determined using analysis of variance (ANOVA) followed by multiple comparison tests with Bonferroni adjustment. Differences in $P$ values $<0.05$ or $<0.01$ were considered statistically significant.

\section{Results}

\section{Effects of SSTW on number of eosinophils and other inflammatory cells in BALF}

To investigate the anti-inflammation effect of SSTW on the eosinophilia in OVA-induced asthmatic mice, we determined the number of total cells including eosinophils and other inflammatory cells in BALF. As shown in Fig. 1, the number of total cells, eosinophils, and other inflammatory cells in the OVA-induced group was significantly higher when compared with the NC group with PBS-induced mice. However, a positive control drug in this study, Mon group dramatically decreased the number of total cells and eosinophils compared with 


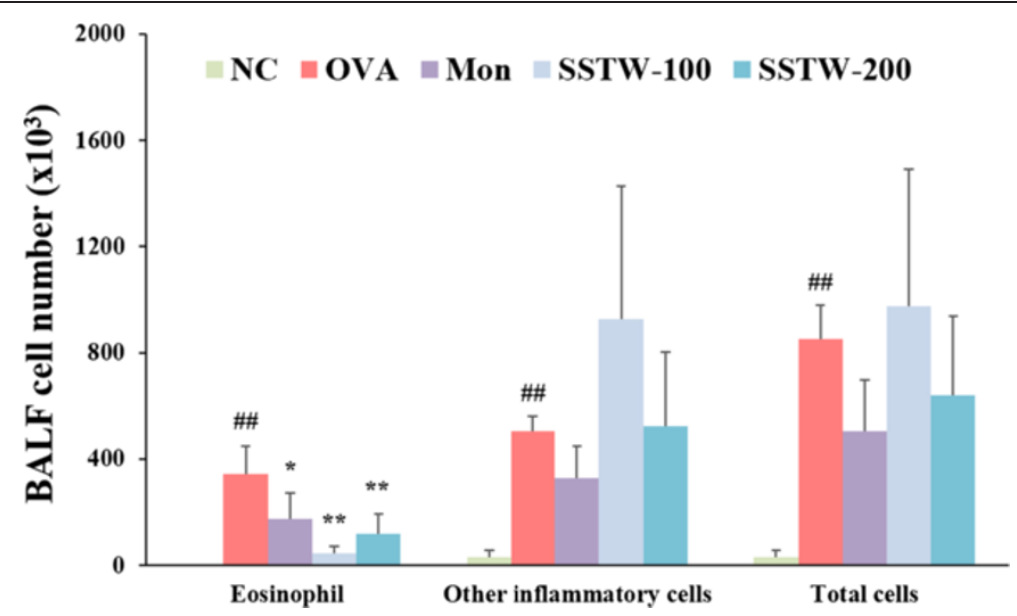

Fig. 1 Effects of SSTW on recruitment of inflammatory cells in BALF of OVA-mice. Cells were isolated by cytospin and stained with Diff-Quick. Cell numbers were determined using a light microscope to count cells in at least five squares of a hemocytometer after excluding dead cells using trypan blue. NC, normal control group (PBS only); OVA, OVA-induced group; Mon, montelukast (30 mg/kg) + OVA-induced group; SSTW-100, SSTW (100 mg/kg) + OVA-induced group; SSTW-200, SSTW (200 mg/kg) + OVA-induced group. Each bar represents the mean \pm SEM $(n=6$ per group). Significant differences at ${ }^{\# \#} P<0.01$ and ${ }^{\#} P<0.05$ compared with the NC group. Significant differences at ${ }^{*} P<0.05$ and ${ }^{* *} P<0.01$ compared with the OVA-induced group

the OVA-induced group. Administration of SSTW (100 and $200 \mathrm{mg} / \mathrm{kg}$ ) strongly exhibited a suppressive effect on eosinophilia influx into BALF.

\section{Effects of SSTW on OVA-induced cytokines and chemo- kine level in BALF}

To determine the possible effects on the T-cell response associated with asthmatic mice, we evaluated the Th2type cytokines and chemokine level in BALF. Figure 2 shows that the OVA-induced group had significantly elevated Th2-type cytokine and chemokine levels compared with the NC group. However, Mon- and SSTW-treated groups (100 and $200 \mathrm{mg} / \mathrm{kg}$ ) had significantly decreased levels of Th2-type cytokines, including IL-4 (Fig. 2a), IL5 (Fig. 2b), IL-13 (Fig. 2c), IL-17 (Fig. 2d), IL-33 (Fig. 2e), and chemokine such as eotaxin (Fig. 2f), compared with those from the OVA-induced group.

\section{Effects of SSTW on inflammatory cell accumulation and mucus production in lung tissue}

To evaluate the inhibitory effect on the histological change in the lung tissue of OVA-induced asthmatic mice, we stained lung sections with H\&E stain solution and PAS. The infiltration of leukocytes in the peribronchial/peribronchiolar lung tissue was not detected in the NC group with PBS-induced mice.

In contrast, the OVA-induced group showed the infiltration of leukocytes such as inflammatory cell accumulation of high density. However, treatment with SSTW (100 and $200 \mathrm{mg} / \mathrm{kg}$ ) effectively suppressed inflammatory cell numbers in lung tissue (Figs. 3a and c). Mucus overproduction in the OVA-induced group was clearly observed as a violet color in the bronchial airways compared with the NC group. However, administration of Mon and SSTW (100 and $200 \mathrm{mg} / \mathrm{kg}$ ) significantly decreased the mucus hypersecretion in lung tissue (Figs. 3b and d).

\section{Effects of SSTW on the release of IgE levels}

To confirm the association with Th2-type responses in the plasma of OVA-induced asthmatic mice, we measured the total and OVA-specific IgE levels in plasma. Total and OVA-specific IgE levels in plasma were markedly elevated in the OVA-induced group compared with the NC group. The Mon and SSTW groups (100 and $200 \mathrm{mg} / \mathrm{kg}$ ) had significantly decreased total and OVAspecific IgE levels in plasma compared with the OVAinduced mice (Figs. 4a and b).

\section{Effects of SSTW on HO-1 level and protein expression}

To determine the HO-1 protein expression associated with asthmatic mice, we evaluated the $\mathrm{HO}-1$ level and protein expression by ELISA and immunohistochemistry. As shown in Fig. 5a, the HO-1 level in homogenized lung tissue significantly increased in the OVA-induced group compared with the NC group. Moreover, administration of SSTW (100 and $200 \mathrm{mg} / \mathrm{kg}$ ) gradually increased more than the OVA-induced group in a dosedependent manner. These results were consistent with immunohistochemistry analysis. HO-1 protein expression markedly increased in the OVA-induced group compared with the NC group. SSTW treatment (100 and $200 \mathrm{mg} / \mathrm{kg}$ ) strongly increased $\mathrm{HO}-1$ protein expression compared with the OVA-induced group (Fig. 5b). 

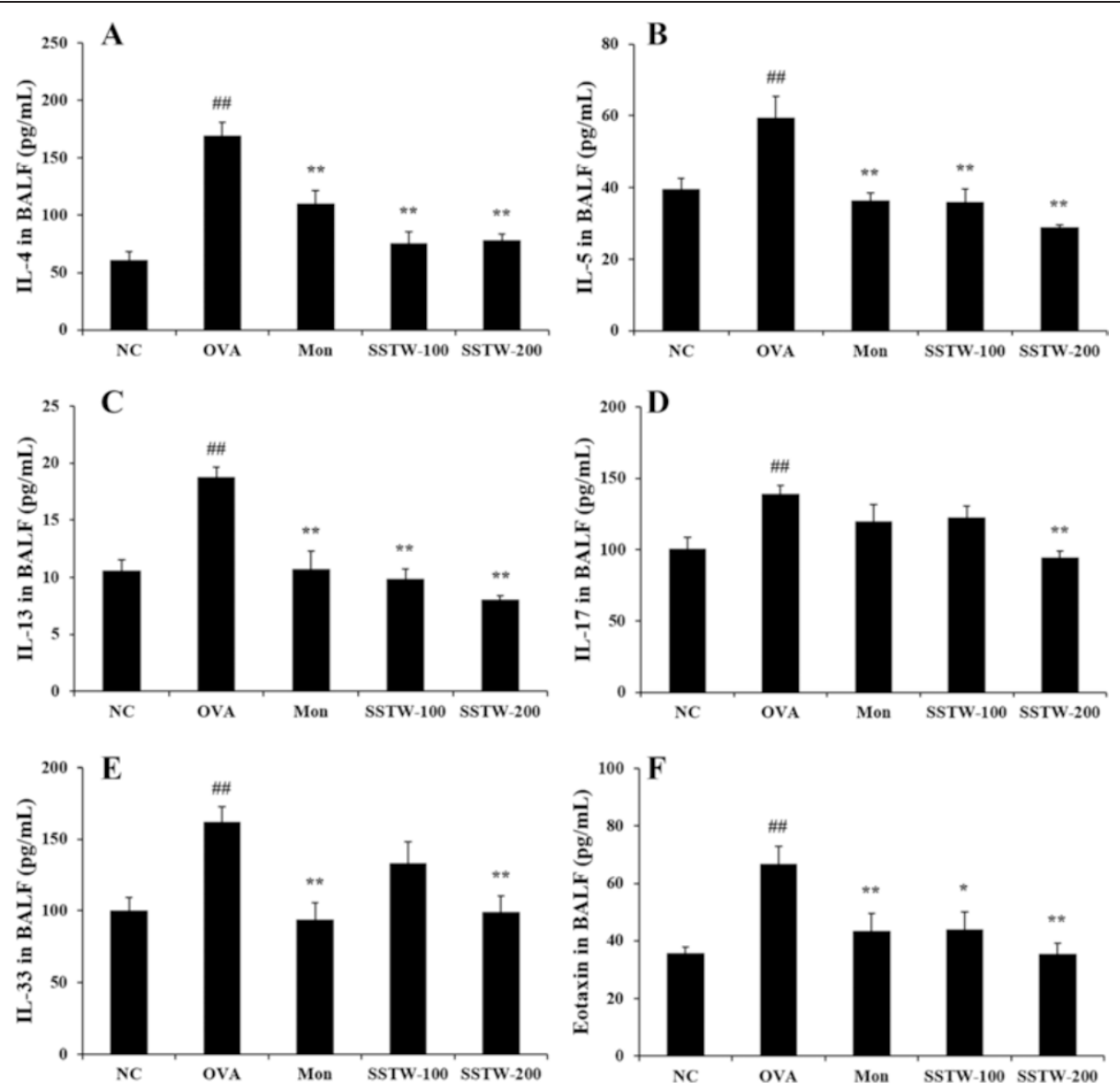

Fig. 2 Effects of SSTW on cytokine and chemokine levels in BALF. Individual values were obtained using ELISA analysis. (a) IL-4 level; (b) IL-5 level; (c) IL-13 level; (d) IL-17 level; (e) IL-33 level; (f) eotaxin level. NC, normal control group (PBS only); OVA, OVA-induced group; Mon, montelukast (30 mg/kg) + OVA-induced group; SSTW-100, SSTW (100 mg/kg) + OVA-induced group; SSTW-200, SSTW (200 mg/kg) + OVA-induced group. Each bar represents the mean \pm SEM ( $n=6$ per group). Significant differences at ${ }^{\# \#} P<0.01$ compared with the NC group. Significant differences at ${ }^{*} P<0.05$ and ${ }^{* *} P<0.01$ compared with the OVA-induced group

\section{Discussion}

The objective of this study was to evaluate the antiasthmatic effect of SSTW in an asthma-induced mouse model by OVA. We investigated the influx of inflammatory cells (particularly, eosinophils) and Th2-type cytokines including IL-4, IL-5, IL-13, IL-17, IL-33, and chemokine (eotaxin) into the BALF, IgE levels in plasma, inflammatory cell infiltration, mucus production, and HO-1 protein expression in lung tissue. Our results indicate that SSTW significantly decreased the airway inflammation by suppressing the influx of inflammatory cells as eosinophilia, increased Th2-type cytokines, chemokine, IgE levels, and mucus hypersecretion, and gradually increased the $\mathrm{HO}-1$ expression related to oxidative stress.

Soshiho-tang is a traditional herbal medicine used specifically to treat alternating chills and fever, hardness and fullness in the hypochondrium, dry retching, and bitter taste in the mouth. Moreover, it is probably one of the most extensively investigated herbal formulas as experimental and clinical data have been accumulating worldwide [13]. Based on previous studies, among the constituents of the mixed herbal Soshiho-tang, we can assume that the beneficial effects in this allergic asthma model are via the antiasthmatic effect of Pinelliae Tuber [20], the antiallergic effect of Zingiberis Rhizoma Crudus [21], the anti-inflammatory effect of Scutellariae Radix [22], Ginseng Radix [23], and Zizyphi Fructus [24], the antioxidant effect of Glycyrrhizae Radix et Rhizoma [25], and the hemolytic activities of Bupleuri Radix [26]. The composition of SSTW was analyzed using high performance liquid chromatography (HPLC) in previous study [27]. The chemical standards used to identify and quantify compounds in the SSTW were as follows: liquritin, glycyrrhizin and baicalin (marker components). Previous studies demonstrated that the compounds exerts multiple biological functions and pharmacological effects such as anti-inflammatory effect of liquritin [28], and antioxidant effect of glycyrrhizin [29] and antiallergy effect of baicalin [30]. The present study aimed to investigate whether SSTW has antiallergic effects related to 

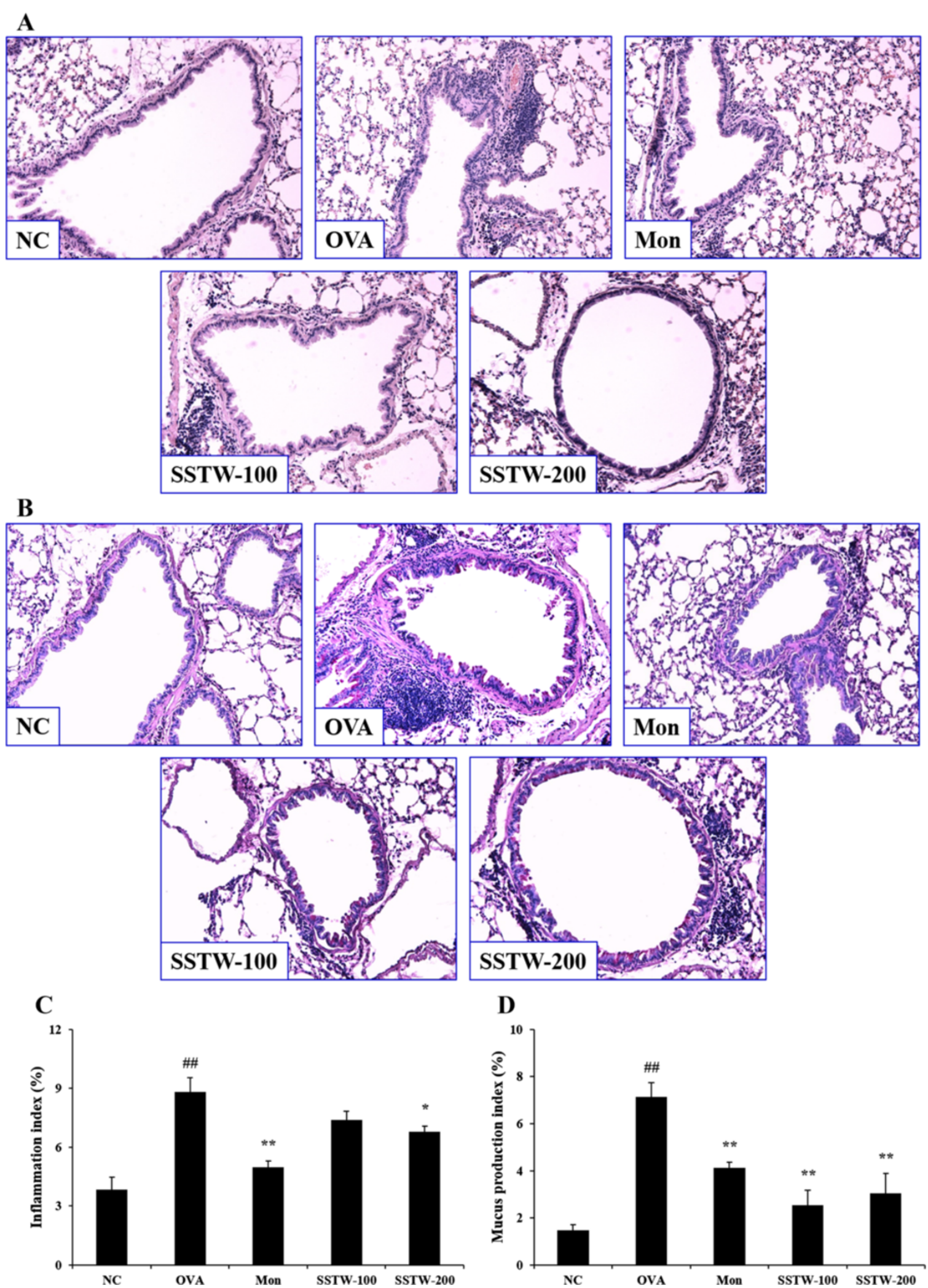

Fig. 3 (See legend on next page.) 
(See figure on previous page.)

Fig. 3 Effects of SSTW on recruitment of leukocytes and mucus production in lung tissue. Lung tissues were stained with (a) H\&E and (b) periodic acid-Schiff (PAS) solution (magnification $200 \times$ ). $\mathbf{a}$ and $\mathbf{b}$ Representative photomicrographs of lung sections are shown ( $\mathrm{n}=6 \mathrm{per}$ group). c Inflammation index and (d) mucus production index were determined using an image analyzer. NC, normal control group (PBS only); OVA, OVA-induced group; Mon, montelukast (30 mg/kg) + OVA-induced group; SSTW-100, SSTW (100 mg/kg) + OVA-induced group; SSTW-200, SSTW (200 mg/kg) + OVA-induced group. Each bar represents the mean \pm SEM ( $n=6$ per group). Significant differences at ${ }^{\# \# ~} P<0.01$ compared with the NC group. Significant differences at ${ }^{*} P<0.05$ and ${ }^{* *} P<0.01$ compared with the OVA-induced group

inflammation effects through modulation of the production of Th2-type cytokines.

The obvious mechanisms of chronic airway inflammation in asthma are incompletely known but are considered to be dependent on the sustained infiltration and activation of numerous inflammatory cells including eosinophils, neutrophils, lymphocytes, and macrophages, followed by synthesis and release of a variety of proinflammatory mediators and cytokines [31]. In particular, among the activated cells in the pathogenesis of allergic asthma, eosinophils are the most prominent cell type, and an increased number in the airways is correlated

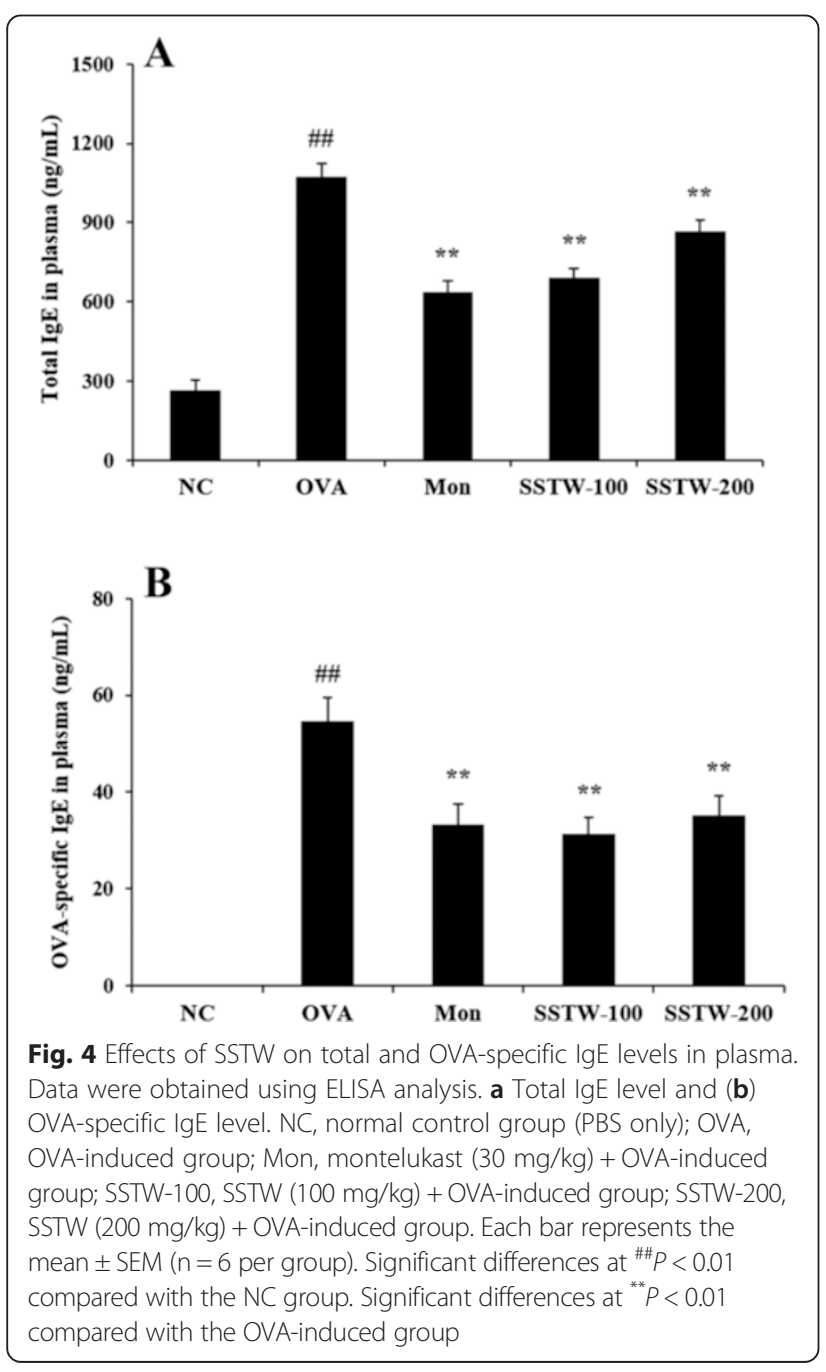

with the severity of asthma [32]; accordingly, selective elimination of eosinophils is often a target for the therapy of various inflammatory diseases including allergic asthma. A previous study demonstrated that recruitment of eosinophils into BALF was clearly observed as expected in the OVA-induced asthmatic mice [19]. Administration of SSTW dramatically decreased the number of eosinophils in BALF. Our results indicate that SSTW is an effective eosinophil-depleting agent. In addition, several mediators secreted from eosinophils and lymphocytes can amplify portions of the inflammatory cascade; they can increase airway hyperresponsiveness, inflammatory cell accumulation, and stimulate mucus secretion, both of which can contribute to airway obstruction and remodeling [33]. In our study, we found elevated leukocyte infiltration, goblet-cell hyperplasia, and mucus hypersecretion, confirming a previous study [19]. To support the previous results, our histopathological findings (H\&E and PAS stain) demonstrate that SSTW significantly decreased the OVA-induced leukocyte infiltration, goblet-cell hyperplasia, and mucus hypersecretion.

Initiation of allergic response occurs with allergen presentation by antigen-presenting cells to $\mathrm{CD} 4^{+} \mathrm{T}$ cells. Antigen-activated $\mathrm{CD} 4^{+} \mathrm{T}$ cells induce several characteristic features of asthma, including the secretion of Th2type cytokines such as IL-4, IL-5, and IL-13, which are responsible for IgE production by B cells and eosinophil activation and recruitment [34, 35]. IL-4 is the most important Th2-type cytokine in inducing isotype switching to IgE in B lymphocytes [36]. IL-5 plays a major role in the maturation and recruitment of eosinophils into the airway [37]. IL-13 induces many features of allergic lung disease, including goblet cell metaplasia and mucus hypersecretion, which all contribute to airway obstruction [38]. IL-17 induces the production of many other cytokines (such as IL-6, G-CSF, GM-CSF, IL-1 $\beta$, TGF- $\beta$, and TNF- $\alpha$ ), chemokines, and prostaglandins (e.g., PGE2) from many cell types such as fibroblasts, endothelial cells, epithelial cells, keratinocytes, and macrophages [39]. IL-33 is a potent inducer of proinflammatory cytokine and chemokine production by mast cells. It also induces the degranulation of IgE-primed mast cells and enhances mastcell maturation and survival [40]. Eotaxin plays a role in airway remodeling through recruitment of eosinophils and mast cells, which have profibrogenic activity [41]. Thus, these Th2-type cytokines induce inflammatory responses, 


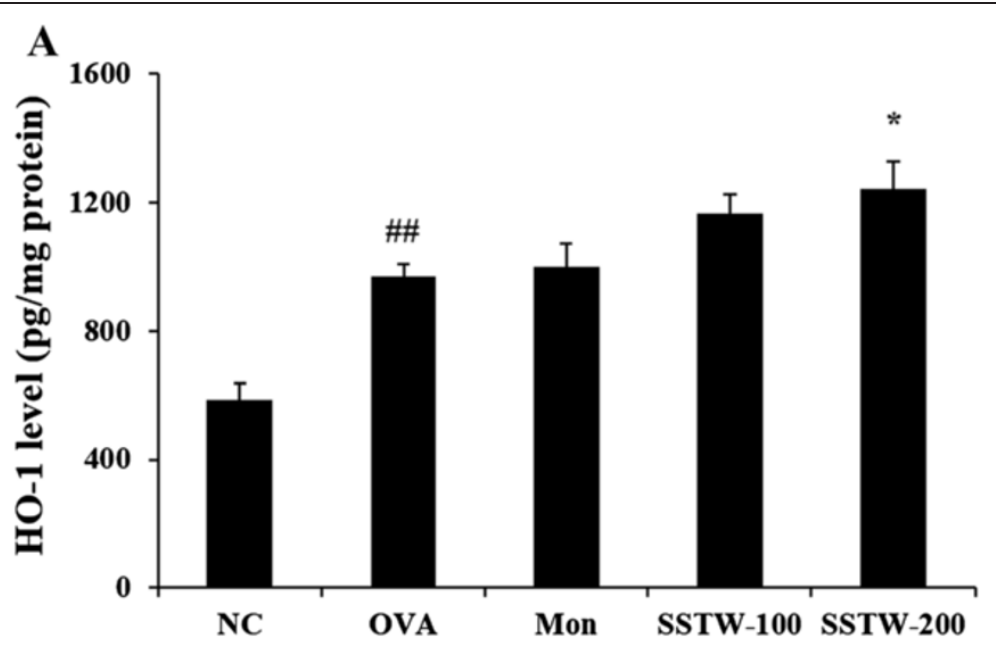

B
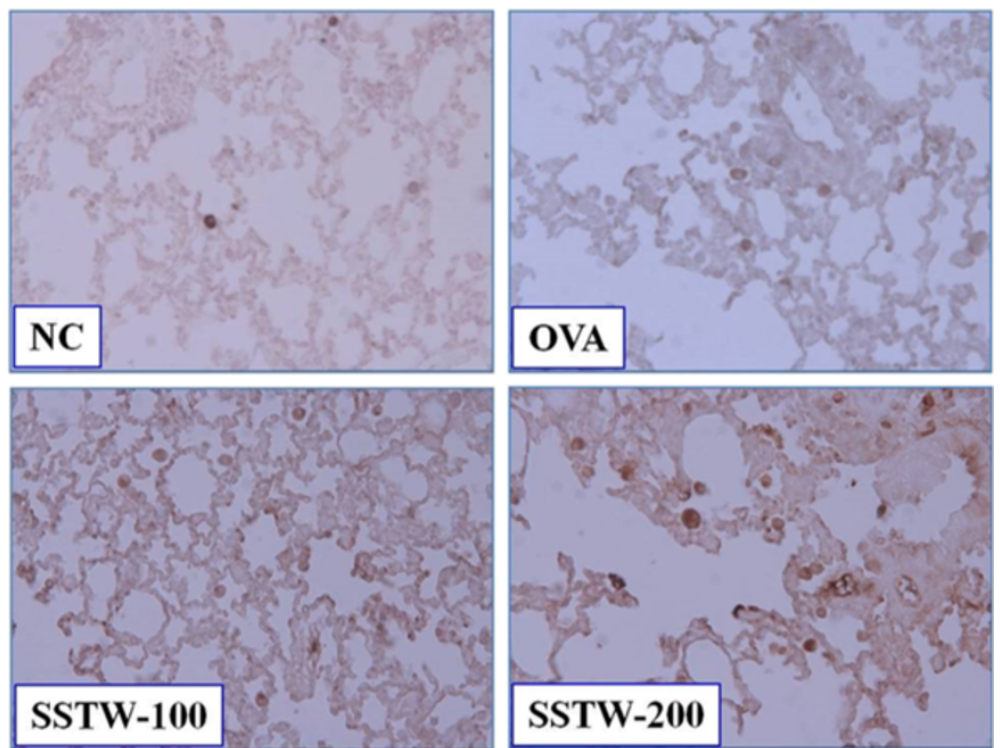

Fig. 5 Effects of SSTW on HO-1 level and protein expression. Data were obtained using (a) ELISA analysis and (b) immunohistochemistry. NC, normal control group (PBS only); OVA, OVA-induced group; Mon, montelukast (30 mg/kg) + OVA-induced group; SSTW-100, SSTW (100 mg/kg) + OVAinduced group; SSTW-200, SSTW (200 mg/kg) + OVA-induced group. Each bar represents the mean \pm SEM ( $n=6$ per group). Significant differences at ${ }^{\# \#} P<0.01$ compared with the NC group. Significant differences at ${ }^{*} P<0.05$ compared with the OVA-induced group

such as inflammatory cells infiltration, eosinophil activation, IgE production, and mucus secretion [42]. Many studies suggest that the anti-inflammatory effects of Th2type cytokines occur via diminishing its production in a mouse model of allergic asthma [43, 44]. Our findings indicate that SSTW significantly decreased Th2-type cytokine production. This anti-inflammatory effect of SSTW may be responsible, at least in part, for the decreased recruitment of eosinophils into the lung. IgE may be an important target in treatments for allergy and asthma and is closely associated with Th2-type responses. Administration of SSTW markedly attenuated the increased total and OVA-specific IgE levels in plasma. These findings support the evidence that SSTW regulates the Th2-type immune response in an asthmatic mouse model. Therefore, SSTW may have potential as an effective antiasthma agent through decrease of IgE levels.

An imbalance between the oxidative forces and the antioxidant defense systems favoring an oxidative injury has been implicated in the pathogenesis of asthma [45]. Oxidative injury leads to an augmentation of the existing inflammation that is a hallmark of asthma. One of these defense mechanisms is the induction of a stress-response protein, HO-1. Therefore, to determine a factor related to oxidative stress we measured $\mathrm{HO}-1$ expression. $\mathrm{HO}-1$, a protective gene, is a highly inducible enzyme that defends cells against oxidative stress and is induced in a mouse model of asthma. Moreover, its deficiency leads to an 
increase in chronic inflammation and leukocyte recruitment [46]. Previous studies reveal that the induction of HO-1 helps to reduce tissue injury and inflammation in a models of experimental asthma [47-49]. It was suggested that $\mathrm{HO}-1$ induction occurs as a protective mechanism against oxidant-mediated cellular injury representing reactive oxygen species production [50]. Our results confirm that SSTW overexpressed OVA-induced production of $\mathrm{HO}-1$, suggesting that the protective effect of SSTW is related to its reduction of oxidative stress. Increased HO-1 protein expression may be due to the induction of the enzyme by inflammatory mediators present in the asthmatic airway. Many cytokines and oxidants involved in asthmatic inflammation including interleukins are able to induce HO-1 expression in cell lines and tissues under experimental conditions [51]. Taken together, our findings demonstrate that SSTW provides cytoprotection through overexpression of HO-1 induced by Th2-type cytokines.

Mon is a CysLT 1 receptor antagonist used for the maintenance treatment of asthma to relieve allergic symptoms. Mon inhibits the action of leukotriene $\mathrm{D}_{4}$ on the CysLT receptor in the lung, which reduces bronchoconstriction and airway inflammation $[52,53]$. In present study, Mon reduces the eosinophilic airway inflammation, and decrease the release of Th2-type cytokines, chemokine, $\mathrm{IgE}$ and mucus hypersecretion. However, the regulation of HO-1 have not worked. Treatment of SSTW reduces asthmatic responses by providing similar result to Mon. In addition, activation of HO-1 attenuated airway inflammation by administration of SSTW in mice with OVA-induced asthma. Considering the overall results, our findings demonstrate that SSTW exerts antiasthmatic effects on OVA-induced airway inflammation, and that HO-1 induction may be at least partly responsible for its action.

\section{Conclusions}

Our findings demonstrate that SSTW significantly inhibits OVA-induced asthmatic reaction by reduction of leukocytes, eosinophilic inflammation and downregulation of Th2-type cytokines, chemokines, and decrease of mucus hypersecretion, IgE levels and upregulation of HO-1 expression. Therefore, SSTW may prove to be a useful therapeutic agent for the treatment of allergic airway diseases.

\footnotetext{
Abbreviations

ANOVA: Analysis of variance; BALF: Bronchoalveolar lavage fluid; $\mathrm{CysLT}_{1}$ : Cysteinyl leukotriene 1; ELISA: Enzyme-linked immunosorbent assay; HO: Heme oxygenase; H\&E: Hematoxylin and eosin; Ig: Immunoglobulin; IL: Interleukin; Mon: Montelukast; OVA: Ovalbumin; PAS: Periodic acid - Schiff; SEM: Standard error of the mean; SSTW: Soshiho-tang water extract; Th2: T helper 2.
}

\section{Competing of interests}

The authors declare that they have no competing interests.

\section{Authors' contributions}

WYJ, HKS, SKK, and MYL participated in the design of the study, data analyses, and manuscript preparation. WYJ, ISS, and MYL conducted the assays and analyses. All authors read and approved the final manuscript.

\section{Acknowledgments}

This research was part of a project (Construction of Scientific Evidences for Herbal Medicine Formulas, K15251) funded by the K-herb Research Center in Korea Institute of Oriental Medicine.

\section{Author details}

${ }^{1} \mathrm{~K}$-herb Research Center, Korea Institute of Oriental Medicine, 1672 Yuseong-daero, Yuseong-gu, Daejeon 305-811, Republic of Korea. ${ }^{2}$ College of Veterinary Medicine, Chonnam National University, 77 Yongbong-ro, Buk-gu, Gwangju 500-757, Republic of Korea. ${ }^{3}$ College of Pharmacy, Chungnam National University, 99 Daehak-ro, Yuseong-gu, Daejeon 305-764, Republic of Korea.

Received: 18 June 2015 Accepted: 11 September 2015

Published online: 18 September 2015

\section{References}

1. Bosnjak B, Stelzmueller B, Erb KJ, Epstein MM. Treatment of allergic asthma: modulation of Th2 cells and their responses. Respir Res. 2011;12:114.

2. Issekutz AC, Sapru K. Modulation of adjuvant arthritis in the rat by 2methoxyestradiol: an effect independent of an anti-angiogenic action. Int Immunopharmacol. 2008;8:708-16.

3. Gauvreau GM, Boulet LP, Cockcroft DW, Fitzgerald JM, Carlsten C, Davis BE, et al. Effects of interleukin-13 blockade on allergen-inducedairway responses in mild atopic asthma. Am J Respir Crit Care Med. 2011;183:1007-14.

4. Zhu J, Paul WE. CD4 T cells: fates, functions, and faults. Blood. 2008;112:1557-69.

5. Umetsu DT, DeKruyff RH. TH1 and TH2 CD4+ cells in human allergic diseases. J Allergy Clin Immunol. 1997;100:1-6.

6. Punnonen J, Aversa G, Cocks BG, de Vries JE. Role of interleukin-4 and interleukin-13 in synthesis of IgE and expression of CD23 by human B cells. Allergy. 1994:49:576-86.

7. Horváth I, Donnelly LE, Kiss A, Paredi P, Kharitonov SA, Barnes PJ. Raised levels of exhaled carbon monoxide are associated with an increased expression of heme oxygenase-1 in airway macrophages in asthma: a new marker of oxidative stress. Thorax. 1998;53:668-72.

8. Pae HO, Oh GS, Choi BM, Chae SC, Chung HT. Differential expressions of heme oxygenase-1 gene in CD25- and CD25+ subsets of human CD4+ T cells. Biochem Biophys Res Commun. 2003;306:701-5.

9. Ryter SW, Choi AM. Heme oxygenase-1: redox regulation of a stress protein in lung and cell culture models. Antioxid Redox Signal. 2005;7:80-91.

10. Ohtake N, Nakai Y, Yamamoto M, Ishige A, Sasaki H, Fukuda K, et al. The herbal medicine Shosaiko-to exerts different modulating effects on lung local immune responses among mouse strains. Int Immunopharmacol. 2002:2:357-66.

11. Amagaya S, Umeda M, Ogihara Y. Inhibitory action of shosaikoto and daisaikoto (traditional Chinese medicine) on collagen-induced platelet aggregation and prostaglandin biosynthesis. Planta Med. 1986;5:345-9.

12. Sakaguchi S, Tsutsumi E, Yokota K. Preventive effects of a traditional Chinese medicine (sho-saiko-to) against oxygen toxicity and membrane damage during endotoxemia. Biol Pharm Bull. 1993;16:782-6.

13. Kang H, Choi TW, Ahn KS, Lee JY, Ham IH, Choi HY, et al. Upregulation of interferon- $\gamma$ and interleukin-4, Th cell-derived cytokines by So-Shi-Ho-Tang (Sho-Saiko-To) occurs at the level of antigen presenting cells, but not CD4 T cells. J Ethnopharmacol. 2009;123:6-14.

14. Kim Y, Lee MY, Kim OS, Jeon WY, Shin HK. Acute oral toxicity of Insampaedok-san, a traditional herbal formula, in rats and its protective effects against ovalbumin-induced asthma via anti-inflammatory and antioxidant properties. BMC Complement Altern Med. 2014;14:365.

15. Jeon WY, Shin IS, Shin HK, Lee MY. Samsoeum water extract attenuates allergic airway inflammation via modulation of Th1/Th2 cytokines and decrease of iNOS expression in asthmatic mice. BMC Complement Altern Med. 2015;15:47.

16. Lynch KR, O'Neill GP, Liu Q, Im DS, Sawyer N, Metters KM, et al. Characterization of the human cysteinyl leukotriene CysLT1 receptor. Nature. 1999;399:789-93. 
17. Korenblat PE, Antileukotriene Working Group. The role of antileukotrienes in the treatment of asthma. Ann Allergy Asthma Immunol. 2001;86:31-9.

18. Shin IS, Lee MY, Ha H, Jeon WY, Seo CS, Shin HK. Dianthus superbus fructus suppresses airway inflammation by downregulating of inducible nitric oxide synthase in an ovalbumin-induced murine model of asthma. J Inflamm (Lond). 2012;9:41.

19. Lee MY, Seo CS, Lee JA, Lee NH, Kim JH, Ha H, et al. Anti-asthmatic effects of Angelica dahurica against ovalbumin-induced airway inflammation via upregulation of heme oxygenase-1. Food Chem Toxicol. 2011;49:829-37.

20. Song JJ, Park YC. Effects of Pinelliae Rhizoma on immunocyte and cytokine production in asthma model mouse. Korean J Orient Int Med. 2005;26:156-68 (in Korean).

21. Tewtrakul S, Subhadhirasakul S. Anti-allergic activity of some selected plants in the Zingiberaceae family. J Ethnopharmacol. 2007;109:535-8.

22. Yoon SB, Lee YJ, Park SK, Kim HC, Bae H, Kim HM, et al. Anti-inflammatory effects of Scutellaria baicalensis water extract on LPS-activated RAW264.7 macrophages. J Ethnopharmacol. 2009;125:286-90.

23. Paul S, Shin HS, Kang SC. Inhibition of inflammations and macrophage activation by ginsenoside-Re isolated from Korean ginseng (Panax ginseng C.A. Meyer). Food Chem Toxicol. 2012;50:1354-61.

24. Goyal R, Sharma PL, Singh M. Possible attenuation of nitric oxide expression in anti-inflammatory effect of Ziziphus jujuba in rat. J Nat Med. 2011;65:514-8.

25. Yoon MY, Jun KI, Son ES, Kim JH, Kim YS, Park EJ, et al. Induction of Glutathione S-transferase activity by the extracts of Glycyrrhiza uralensis Fischer. J Korean Soc Appl Biol Chem. 2008:51:228-32 (in Korean).

26. Sun HX. Haemolytic activities and adjuvant effect of Bupleurum chinense saponins on the immune responses to ovalbumin in mice. Vaccine. 2006;24:1324-31.

27. Kim JH, Ha H, Seo CS, Lee JA, Shin HK. Simultaneous determination of baicalin and glycyrrhizin in Sosiho-tang by HPLC and anti-inflammatory activity. Kor J Herbology. 2011;26:41-6.

28. Yu JY, Ha JY, Kim KM, Jung YS, Jung JC, Oh S. Anti-Inflammatory Activities of Licorice Extract and Its Active Compounds, Glycyrrhizic Acid, Liquiritin and Liquiritigenin, in BV2 Cells and Mice Liver. Molecules. 2015;20:13041-54.

29. Yildirim AO, Ince M, Eyi YE, Tuncer SK, Kaldirim U, Eroglu M, et al. The effects of glycyrrhizin on experimental acute pancreatitis in rats. Eur Rev Med Pharmacol Sci. 2013;17:2981-7.

30. Ma C, Ma Z, Fu Q, Ma S. Anti-asthmatic effects of baicalin in a mouse mode of allergic asthma. Phytother Res. 2014;28:231-7.

31. Maddox L, Schwartz DA. The pathophysiology of asthma. Annu Rev Med 2002;53:477-98.

32. Bousquet J, Clark TJ, Hurd S, Khaltaev N, Lenfant C, O'byrne P, et al. GINA guidelines on asthma and beyond. Allergy. 2007;62:102-12.

33. Walker C, Kaegi MK, Braun P, Blaser K. Activated T cells and eosinophilia in bronchoalveolar lavages from subjects with asthma correlated with disease severity. J Allergy Clin Immunol. 1991;88:935-42.

34. Hogan MB, Weissman DN, Hubbs AF, Gibson LF, Piktel D, Landreth KS. Regulation of eosinophilopoiesis in a murine model of asthma. J Immunol. 2003;171:2644-51.

35. Taube C, Dakhama A, Gelfand EW. Insights into the pathogenesis of asthma utilizing murine models. Int Arch Allergy Immunol. 2004;135:173-86.

36. Finkelman FD, Holmes J, Katona IM, Urban Jr JF, Beckmann MP, Park LS, et al. Lymphokine control of in vivo immunoglobulin isotype selection. Annu Rev Immunol. 1990;8:303-33.

37. Robinson DS, North J, Zeibecoglou K, Ying S, Meng Q, Rankin S, et al. Eosinophil development and bone marrow and tissue eosinophils in atopic asthma. Int Arch Allergy Immunol. 1999;118:98-100.

38. Wills-Karp M, Luyimbazi J, Xu X, Schofield B, Neben TY, Karp CL, et al. Interleukin-13: central mediator of allergic asthma. Science. 1998;282:2258-61.

39. Aggarwal S, Gurney AL. IL-17: prototype member of an emerging cytokine family. J Leukoc Biol. 2002;71:1-8.

40. Allakhverdi Z, Smith DE, Comeau MR, Delespesse G. Cutting edge: The ST2 ligand IL-33 potently activates and drives maturation of human mast cells. J Immunol. 2007;179:2051-4.

41. Puxeddu I, Bader R, Piliponsky AM, Reich R, Levi-Schaffer F, Berkman N. The CC chemokineeotaxin/CCL11 has a selective profibrogeniceffect on human lung fibroblasts. J Allergy Clin Immunol. 2006;117:103-10.

42. Corrigan CJ, Kay AB. T cells and eosinophils in the pathogenesis of asthma. Immunol Today. 1992;13:501-7.
43. Kim SH, Kim BK, Lee YC. Antiasthmatic effects of hesperidin, a potential Th2 cytokine antagonist, in a mouse model of allergic asthma. Mediators Inflamm. 2011;2011:485402

44. Lee JS, Yang EJ, Yun CY, Kim DH, Kim IS. Suppressive effect of Petasites japonicus extract on ovalbumin-induced airway inflammation in an asthmatic mouse model. J Ethnopharmacol. 2011:133:551-7.

45. Owen S, Pearson D, Suarez-Mendez V, O'Driscoll R, Woodcock A. Evidence of free-radical activity in asthma. N Engl J Med. 1991;325:586-7.

46. Willis D, Moore AR, Frederick R, Willoughby DA. Heme oxygenase: a novel target for the modulation of the inflammatory response. Nat Med. 1996:2:87-90.

47. Kitada O, Kodama T, Kuribayashi K, Ihaku D, Fujita M, Matsuyama T, et al. Heme oxygenase-1 (HO-1) protein induction in a mouse model of asthma. Clin Exp Allergy. 2001;31:1470-7.

48. Zhang Y, Zhang $\mathrm{L}, \mathrm{Wu}$ J, Di C, Xia Z. Heme oxygenase-1 exerts a protective role in ovalbumin-induced neutrophilic airway inflammation by inhibiting Th17 cell-mediated immune response. J Biol Chem. 2013;288:34612-26.

49. Xu J, Zhu YT, Wang GZ, Han D, Wu YY, Zhang DX, et al. The PPARY agonist, rosiglitazone, attenuates airway inflammation and remodeling via heme oxygenase-1 in murine model of asthma. Acta Pharmacol Sin. 2015;36:171-8.

50. Vogt BA, Alam J, Croatt AJ, Vercellotti GM, Nath KA. Acquired resistance to acute oxidative stress. Possible role of heme oxygenase and ferritin. Lab Invest. 1995;72:474-83

51. Choi AM, Alam J. Heme oxygenase-1: function, regulation, and implication of a novel stress-inducible protein in oxidant-induced lung injury. Am J Respir Cell Mol Biol. 1996:15:9-19.

52. Mullol J, Callejas FB, Méndez-Arancibia E, Fuentes M, Alobid I, MartínezAntón A, et al. Montelukast reduces eosinophilic inflammation by inhibiting both epithelial cell cytokine secretion (GM-CSF, IL-6, IL-8) and eosinophil survival. J Biol Regul Homeost Agents. 2010;24:403-11.

53. Shimbori C, Shiota N, Okunishi H. Effects of montelukast, a cysteinylleukotriene type 1 receptor antagonist, on the pathogenesis of bleomycininduced pulmonary fibrosis in mice. Eur J Pharmacol. 2011;650:424-30.

\section{Submit your next manuscript to BioMed Central and take full advantage of:}

- Convenient online submission

- Thorough peer review

- No space constraints or color figure charges

- Immediate publication on acceptance

- Inclusion in PubMed, CAS, Scopus and Google Scholar

- Research which is freely available for redistribution 